\title{
Environmental hydraulic engineering: a perspective
}

\author{
Hubert Chanson ${ }^{1} \cdot$ John Z. Shi ${ }^{2}$
}

Received: 7 March 2015/Accepted: 8 March 2015

(C) Springer Science+Business Media Dordrecht 2015

Hydraulic engineering is the science of water in motion, and mainly dealing with the interactions between the flowing fluid and its surrounding environment. The technical challenges are huge [2]. The levels of complexity are closely linked with the variety of water systems, the broad range of relevant time and length scales, the variability of water systems from droughts to gigantic floods, the complexity of basic fluid mechanics with non-linear governing equations, natural fluid instabilities, interactions between water, solid, air and biological life, and the total dependence of humanity on water [3]. The challenges are not only scientific but also geo-political, as discussed below. This special issue intends to cover some of recent progresses in understanding environmental flows in hydraulic engineering.

In our history, water resources and water-related issues have been and continue to be present in numerous armed conflicts $[2,11]$. A number of conflicts were directly impacted by natural events (typhoons, tsunamis, wind setup) [7], sometimes considered as natural catastrophes or 'divine' salvation depending upon the side. Historical man-made use of water resources included artificial droughts and floods. Droughts were created by diverting river courses and drying up surface and ground-water reserves: e.g., during the siege of Khara Khoto [12]. Artificial flooding was caused by the construction of a dam and its destruction, and the breaching of dykes [3]. Some related case was the bombing of the Sorpe and Möhne dams during the dam buster campaign in 1943 [13], and the anticipation of German dam destruction at the German-Swiss border to stop the crossing of the Rhine river by the Allied Forces during WWII [9]. Since WWII, international armed conflicts have been numerous, with increasing risks of conflict from competition for water resources and food security with prevailing climate change tendencies [6]. The scope of the relevant

Hubert Chanson

h.chanson@uq.edu.au

1 School of Civil Engineering, The University of Queensland, Brisbane, QLD 4072, Australia

2 State Key Laboratory of Ocean Engineering, School of Naval Architecture, Ocean, and Civil Engineering, Shanghai Jiao Tong University, Shanghai 200030, China 
problems is broad, encompassing civilian water supply and pollution, and environmental disasters [14]. A related challenge is the dramatic shrinking of the Aral Sea [8]. Altogether, the political challenges are formidable. New technical solutions are essential to secure water resources and hydraulic engineers have a key role to contribute.

The 35th World Congress of the International Association for Hydro-Environment Engineering and Research was held on 8-13 September 2013, Chengdu, China. A number of relevant short papers were published in its electronic proceedings of the 35th IAHR World Congress by Tsinghua University Press. As suggested by the Scientific Committee of the Congress, a selection of short papers was made by a selection board for publication as Special Issue on Environmental Hydraulic Engineering in Environmental Fluid Mechanics (Springer). The selection board included: Professor H. Joseph S. Fernando, Professor Zhaoyin Wang, Professor Farhad Yazdandoost, Professor George Constantinescu, Professor John Z. Shi and Professor Chanson. Professors Hubert Chanson and John Z. Shi are co-Guest Editors of this Special Issue. The aim of the Special Issue is to present a group of papers that summarise the state-of-the-art in the knowledge about hydraulic engineering in environmental applications, report recent results of research on environmental hydraulics, and suggest novel pathways of analysis in the area. The current issue contains three papers accepted after a rigorous peer-review process from initially eleven papers agreed to be submitted to the special issue. The deadline for paper submission was 1 March 2014, but papers were received as late as April 2014. The contributions are presented in the issue starting with a study of sediment transport, a turbulence investigation and followed by air-water flow measurements. Altogether here are contributions addressing solid-water flows, monophase flows, as well as gas-water, giving an interesting balance to the topics covered herein.

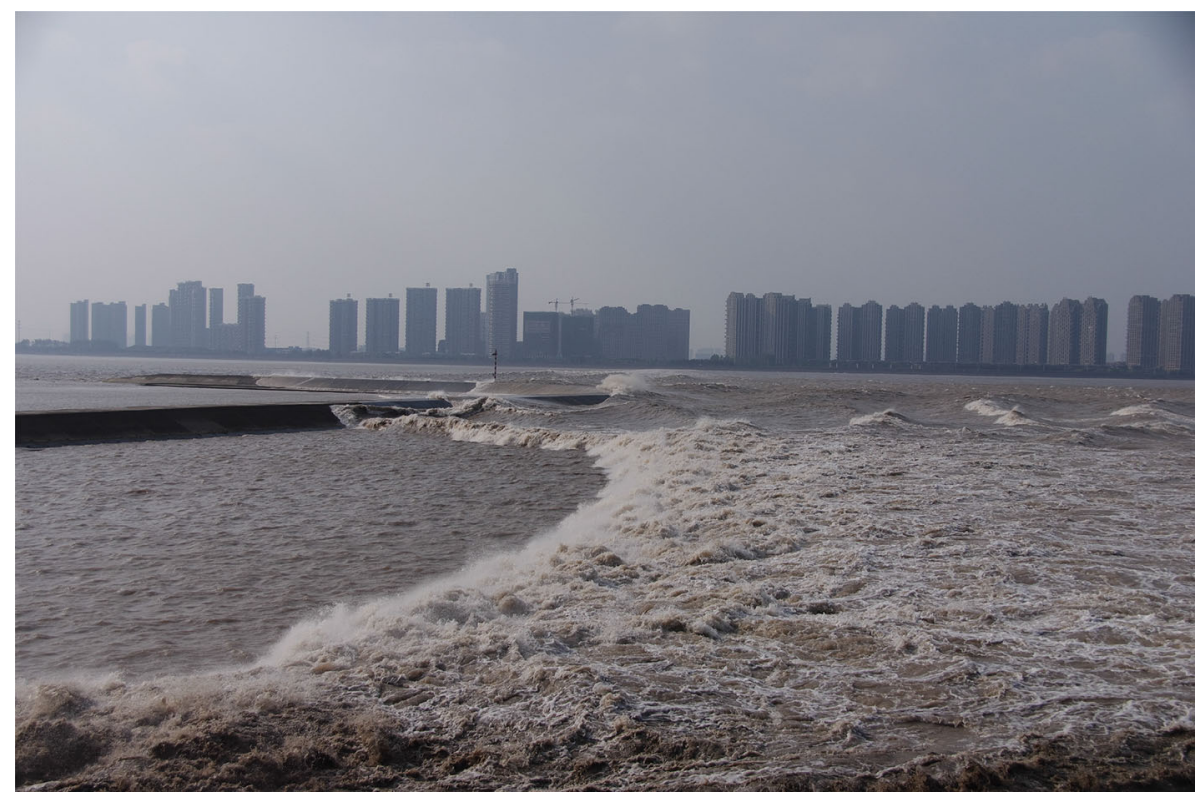

Fig. 1 Tidal bore at the Qiantang River (China) on 12 October 2014 at Meilvba (bore propagation from right to left) - note the massive impact of the bore propagation on the estuarine flow (the river mouth is towards the right) 
The first paper by Khezri and Chanson [5] discusses the onset of non-cohesive sediment particle motion beneath a tidal bore. New experimental measurements of the force terms acting on solid particles beneath a breaking bore and their trajectory characteristics provide a basic understanding of sediment scour conditions. The topic is directly relevant not only to tidal bore affected rivers (Fig. 1), but also tsunami propagation in some rivers, storm surge bores during typhoons and run-up bores in the swash zones. The second contribution by Zhong et al. [15] addresses the role of coherent structures in open channel flows, which has attracted attention for centuries, since the first observations of Leonardo da Vinci (e.g. [10], Pl. XXV). Figure 2 illustrates surface scars in a large river during the flood. Such scars are considered a manifestation of large coherent structures with a free surface [1]. Zhong et al. [15] discuss results obtained with particle image velocimetry (PIV) and their results highlight the interactions between large-scale and super-scale structures. The third paper by Duarte et al. [4] turns the attention to air-water flows, focusing on the effects of entrained air on pressures in a plunge pool, for example, downstream of a ski jump spillway (Fig. 3). The study presents information on pressures inside underlying fissures of the pool bottom beneath the jet impact.

Fig. 2 Scars and large debris at the surface of the Brisbane River (Australia) during the flood in January 2011-photograph taken at Toowong on 12 January 2011 morning about 06:00-looking upstream with the submerged Coronation Drive bicycle path in the foreground

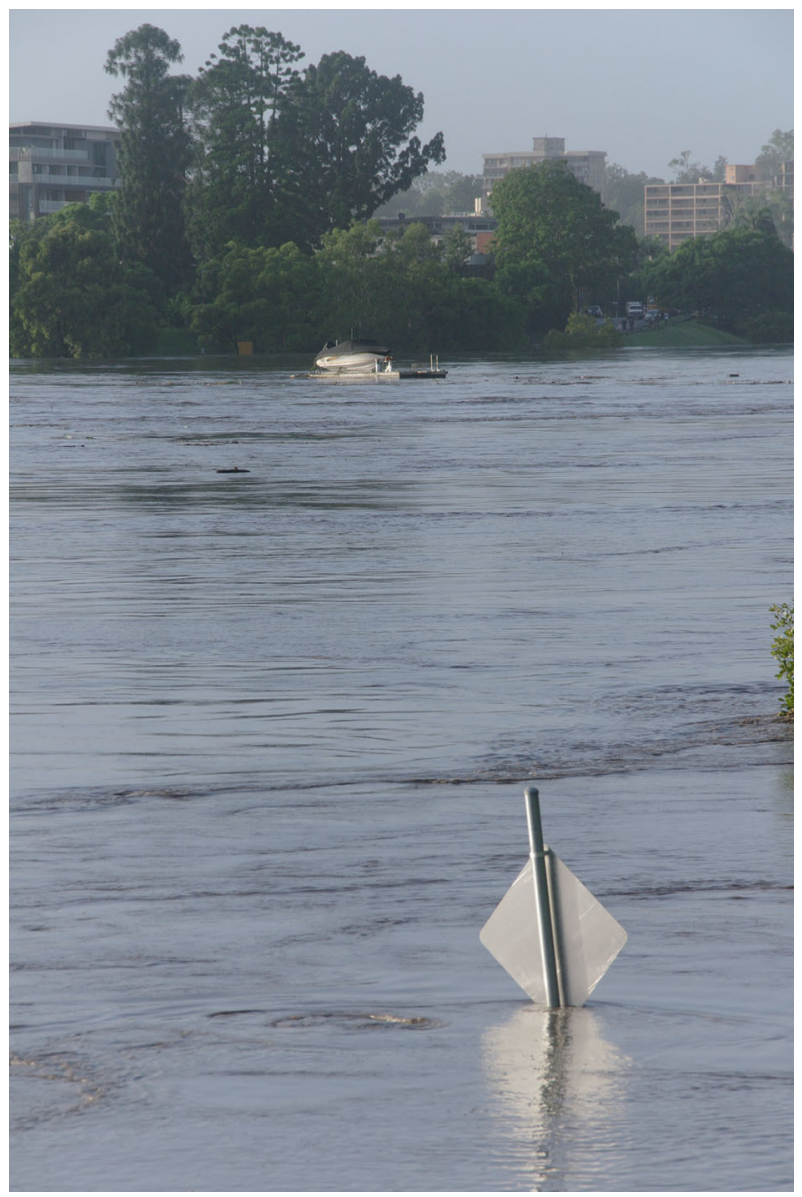




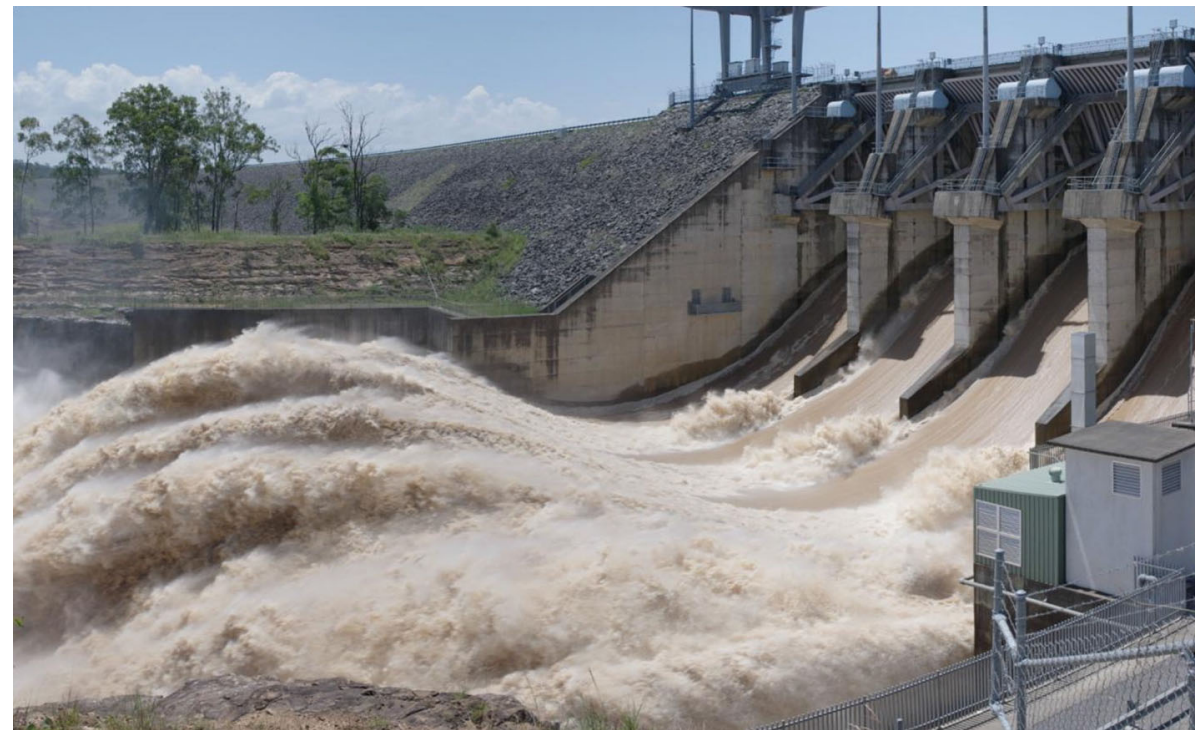

Fig. 3 Wivenhoe Dam spillway ski jump (Australia) during operation on 17 January 2011 at 13:20 (local time)_note the large amount of entrained air in the spillway flow and at the jump take-off

Finally we would like to thank Professor Fernando for entertaining the idea of this Special Issue, and for allowing us to act as its Co-Guest Editors. We also thank the numerous reviewers who significantly contributed to improving the papers presented herein, and the efforts put forward by the authors to complete this issue in a timely manner.

\section{References}

1. Brocchini M, Peregrine DH (2001) The dynamics of strong turbulence at free surfaces. Part 1. Description. J Fluid Mech 449:225-254

2. Chanson H (2004) Environmental hydraulics of open channel flows. Elsevier Butterworth-Heinemann, Oxford, $483 \mathrm{p}$

3. Chanson H (2007) Hydraulic engineering in the 21st century: where to? J Hydraul Res (IAHR) 45(3):291-301

4. Duarte R, Schleiss AJ, Pinheiro A (2015) Influence of jet aeration on pressures around a block embedded in a plunge pool bottom. Environ Fluid Mech 15:21. doi:10.1007/s10652-014-9392-x

5. Khezri N, Chanson H (2015) Turbulent velocity, sediment motion and particle trajectories under breaking tidal bores: simultaneous physical measurements. Environ Fluid Mech 15:18. doi:10.1007/ s10652-014-9358-z. Errata: Environ Fluid Mech 15:1. doi:10.1007/s10652-014-9360-5

6. Kobayashi A (2009) Geographies of peace and armed conflict: introduction. Ann Assoc Am Geogr 99(5):819-826

7. Marktanner M, Mienie E, Noiset L (2015) From armed conflict to disaster vulnerability. Disaster Prev Manag 24(1):53-69. doi:10.1108/DPM-04-2013-0077

8. Micklin P (2007) The Aral Sea disaster. Annu Rev Earth Planet Sci 35:47-72

9. Ré R (1946) Etude du lacher instantané d'une retenue d'eau dans un canal par la méthode graphique (Study of the sudden water release from a reservoir in a channel by a graphical method). La Houille Blanche 1(3): 181-187, 5 plates (in French)

10. Richter JP, Richter IA (1939) The literary works of Leonardo da Vinci, vol 2, 2nd edn. Oxford University Press, London 
11. Stetter S, Herschinger E, Teichler T, Albert M (2011) Conflicts about water: securitizations in a global context. Coop Confl 46(4):441-459

12. Webster D (2002) China's unknown Gobu: alashan. Natl Geogr 201(1):48

13. Webster TM (2005) The dam busters raid: success or sideshow? Air Power Hist 52(Summer):12-25

14. Zemmali A (1995) The protection of water in times of armed conflict. Int Rev Red Cross 308:9

15. Zhong Q, Li D, Chen Q, Wang X (2015) Coherent structures and their interactions in smooth open channel flows. Environ Fluid Mech 15:20. doi:10.1007/s10652-014-9390-z 